\title{
The Statistical Study of Beijing-Tianjin-Hebei Logistics Park Informationization Development
}

\author{
Wu Pingyu, Zhu Lingyao, Li Weipeng, He Rui \\ School of Information, Beijing Wuzi University, Beijing, China \\ Email address: \\ wpydcr@sina.com (Wu Pingyu), 1052992312@qq.com (Zhu Lingyao), walter1900@126.com (Li Weipeng), herui@bwu.edu.cn (He Rui)
}

\section{To cite this article:}

Wu Pingyu, Zhu Lingyao, Li Weipeng, He Rui. The Statistical Study of Beijing-Tianjin-Hebei Logistics Park Informationization Development. Science Journal of Business and Management. Vol. 4, No. 3, 2016, pp. 77-81. doi: 10.11648/j.sjbm.20160403.13

Received: May 8, 2016; Accepted: May 17, 2016; Published: May 28, 2016

\begin{abstract}
The development of science and technology could promote the maturity of Beijing-Tianjin-Hebei's informationization of logistics. Since Logistics Park is an important portion of logistics system, it could be act as a key role in the development of logistics informationaization. This paper describes analysis of Logistics Park information construction situation of the Beijing-Tianjin-Hebei region, not only expounds the functions of existing Logistics Park information construction and service condition, but also the analysis of the deficiency.
\end{abstract}

Keywords: Beijing-Tianjin-Hebei, Logistics Informationization Development, Logistics Park

\section{Introduction}

In recent years, China have put the development of the logistics industry into regional economic development planning, and Logistics Park planning and layout is regarded as an important foundation of the regional logistics development. [1] The government attaches great importance to support the development of the Logistics Park. In September 2013, 12 departments including The National Development and Reform Commission issued the first special Logistics Park planning in China, The National Logistics Park Development Plan; In September 2014, The Mid-long Term Development of Logistics Industry Planning was promulgated by The State Council and The Logistics Park project was list into 12 key projects; In May 2015, The National Development and Reform Commission, The Ministry of Land and Resources, Housing and Urban-rural Development jointly issued The Notice on Logistics Park Demonstration Work. [2]

Based on the wide use of the Internet technology promoting the transformation and upgrading of Logistics Park, some Logistics Parks develop the digital management system and take advantage of computer, network, communication and technologies such as artificial intelligence to manage quantitatively the process of operation, management and service, enhancing the service level of management. Some parks use cloud computing, Internet, GPS and communication network technology and other means to build the hinge of the integrated logistics public information platform, solving the problem of asymmetric information. Cooperate with all Logistics Park information platform for enterprises, promote the "justice" and "ground". Between the park and its connectivity, to automation, informationization, transparency and intelligent direction.

\section{Beijing-Tianjin-Hebei Logistics Park Development Present Situation}

In 2015, the fourth nationwide Logistics Park (base) survey organized by Chinese federation of logistics and purchasing showed that the national Logistics Park number increased steadily and the regional distribution in equilibrium. [3] According to statistics, there are 43 large and medium scale of Logistics Parks in Beijing-Tianjin-Hebei district. Its distribution are not only influenced by the regional economic development level and the population density, but also by different factors such as geographical conditions, area. The higher the level of economic development, population density, the greater the geographic area, the greater the need of Logistics Park. The number of Logistics Park in Beijing is accounted for $21 \%$ of the total number of the Beijing-Tianjin-Hebei district, Tianjin's accounted for $27 \%$, Hebei's accounted for $25 \%$. Beijing-Tianjin-Hebei integration is proposed for the played a 
significant role in the planning and construction of Logistics Park. Beijing-Tianjin-Hebei three areas of Logistics Park number ratio as shown in the figure below (see FIG. 1):

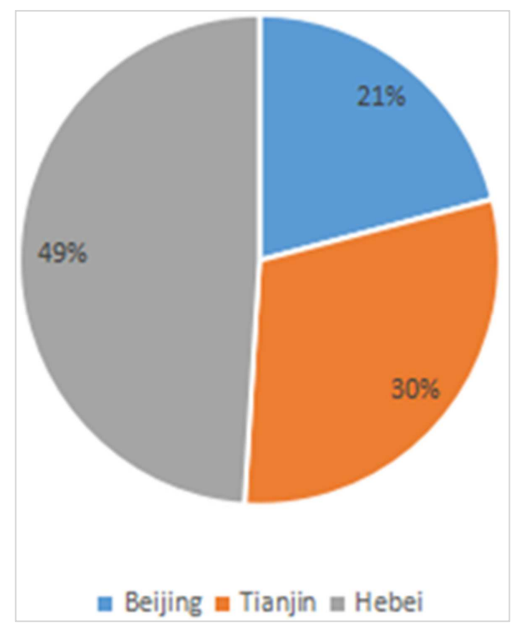

Figure 1. The Logistics Park of Beijing-Tianjin-Hebei quantity.

Logistics Park is not only the area where the logistics operations are concentrated in the transportation ways to concentrate a variety of logistics facilities and different types of logistics enterprises focus on the space layout, but also a certain scale and has a variety of service functions of logistics enterprise rally point. Logistics Park has some characteristics like the multi-function, high level, wide distribution, etc. [4] There are 8 features: comprehensive functions, intensive, information exchange, centralized storage, distribution processing, multimodal transport, the auxiliary services and parking functions. The Logistics Park public information platform can connect each function of Logistics Park of form to others to form a complete process. Informatization construction of Logistics Park is like glue to stick each functional plate together, so the modernization of Logistics Park development needs the support of information technology. With the unceasing improvement of Logistics Park information level, it is better to provide resource information to customers and cooperative enterprises, speed up the working process of the logistics enterprises in the park and improve the efficiency of the whole logistics operation. [5]

\section{Current Situation of the Development of Beijing-Tianjin-Hebei Logistics Park Information Platform}

\subsection{The Concept of the Logistics Park Information Platform}

The Logistics Park information platform is an information exchange platform, using information platform to deal with logistics operations, logistics procedure and logistics management. These work contains collection, classification, selection, storage, analysis, evaluation, feedback, release, manage, and control of general information exchange platform. The Logistics Park information is the best choice for small and medium-sized logistics enterprises to realize logistics informationization. Enterprises could enforce sharing information with other enterprises or their customers only if they access to a logistics information platform. The most usual form is develop a Logistics Park portal. Logistics Park may be regarded as a system, in which the logistics enterprises act as a subsystem, connected to the at all levels and all aspects of these systems is the information platform of Logistics Park, its purpose is to realize the data exchange and information sharing between different logistics enterprises, realize the collaborative operation of the logistics operation. [6]

Modern logistics is based on the highly developed information technology and the integration of modern supply chain. As a highly centralized logistics distribution center, Logistics Park's information construction needs regulators organic linking between the enterprises and parks or government. The direction of modern Logistics Park conduction is to establishing a standard information platform. [7]

Logistics Park information platform is supported by advanced information technology. Logistics information system is its main form of function. Aiming to meet the demand of logistics information system and establish logistics information infrastructure, logistics information could meet the needs of different logistics enterprises logistics service based on the sharing of information. The Logistics Park information platform contains products flow, business flow, information flow and cash flow between enterprises, involving multiple logistics hub, logistics, logistics companies and government departments.

The overall goal of Logistics Park comprehensive information system construction is to form a running management system, which has factors of "safety, green, efficient and intelligent". Its technical architecture conforms to the "comprehensive perception, connectivity, intelligent processing" three characteristics of the Internet of things.

The general information construction of a Logistics Park is beneficial to a highly efficiency cooperate between enterprises and their customers, the construction of green Logistics Park, resource-efficient environmentally friendly development road; the promotion to the gathering of Internet, mobile, Internet of things, building an optimal resource allocation, highest efficiency, safe and reliable, convenient modern wisdom Logistics Park (see FIG. 2).

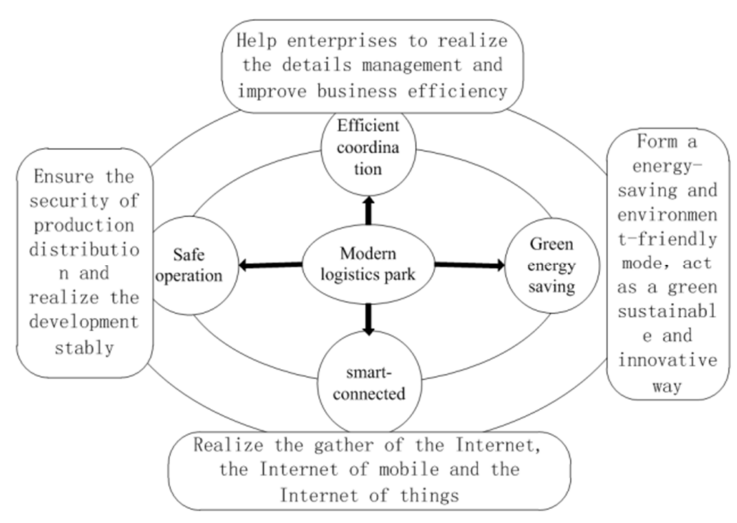

Figure 2. The overall planning of Logistics Park information. 


\subsection{Current Situation of the Development of Beijing-Tianjin-Hebei Logistics Park Information Platform}

Logistics Park information platform is the use of information technology integrated Logistics Park internal business processes, building a modern logistics support to promote the development of high and new technology industry area information system, and the construction of logistics information platform and the modernization of the whole electronic logistics network, etc., making the Logistics
Park development in the direction of the scale management, network operation, thereby greatly improving the efficiency of logistics operation. The level of Logistics Park information service is depends on its size and site operation efficiency.

According to investigation statistics, there is only $26 \%$ Logistics Park in Beijing-Tianjin-Hebei have their own independent web portal. This number is far bellowing the national average, which is $65 \%$. (See figure 3 ). More attention should be paid in the website construction of Logistics Park of Beijing-Tianjin-Hebei.

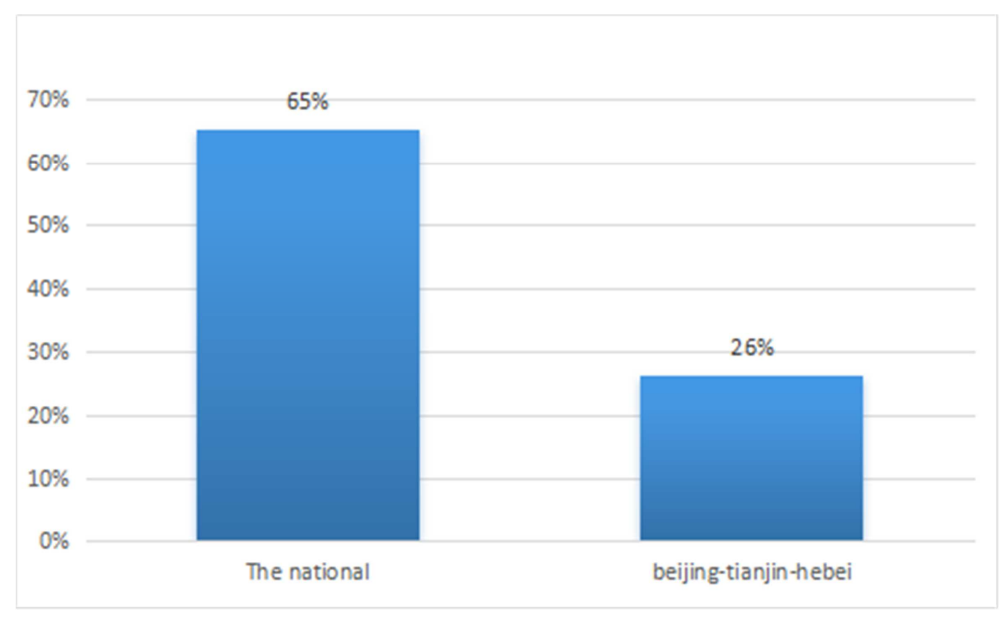

Figure 3. The occupancy rate of independent web portal within Beijing-Tianjin-Hebei's Logistics Park compared with the national average.

According to the data of the questionnaire survey from the report of Logistics Park operation statistical analysis (2015) released by the China federation of logistics and purchasing (see Fig. 4), 2015 north China Logistics Park information system development way with commissioned development is given priority to, still accounts for $53 \%$ of investigation number, compared with 2012 decreased; But the rate of developing their own information system by themselves has risen, accompanying with the rise in ration of purchasing mature products at the same time. These situations suggest that Logistics Parks could develop their own information systems that fit in themselves, according to their business pattern and characteristics. [8]

With the rapid development of mobile Internet, the development of Logistics Park information appears new features; virtual platform is growing rapidly, such as "KaXingTianXia". This kind of platform combines with the concept of Fourth-Party Logistics, through service mode innovation, realizes the integration of information flow, goods flow, and cash flow within one common platform, improving the use efficiency of the logistics resources. With the deeply operation, this kind of virtual platform land quickly. Furthermore, its cooperation with Logistics Park entity platform has developed gradually. This situation not only improves the capacity of the information service platform within Logistics Park, but also promotes the development of its network.

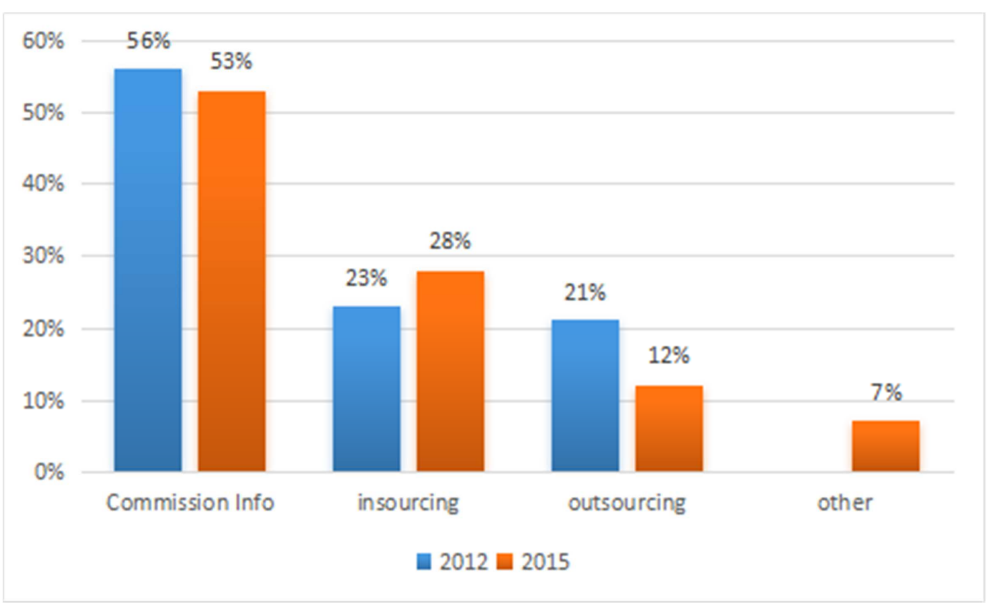

Figure 4. The north of China Logistics Park system's development methods. 
Logistics Park information platform has two main functions (the basic function and the function of the extension) and several extend functions. (See table 1).

Table 1. The function of Logistics Park information platform.

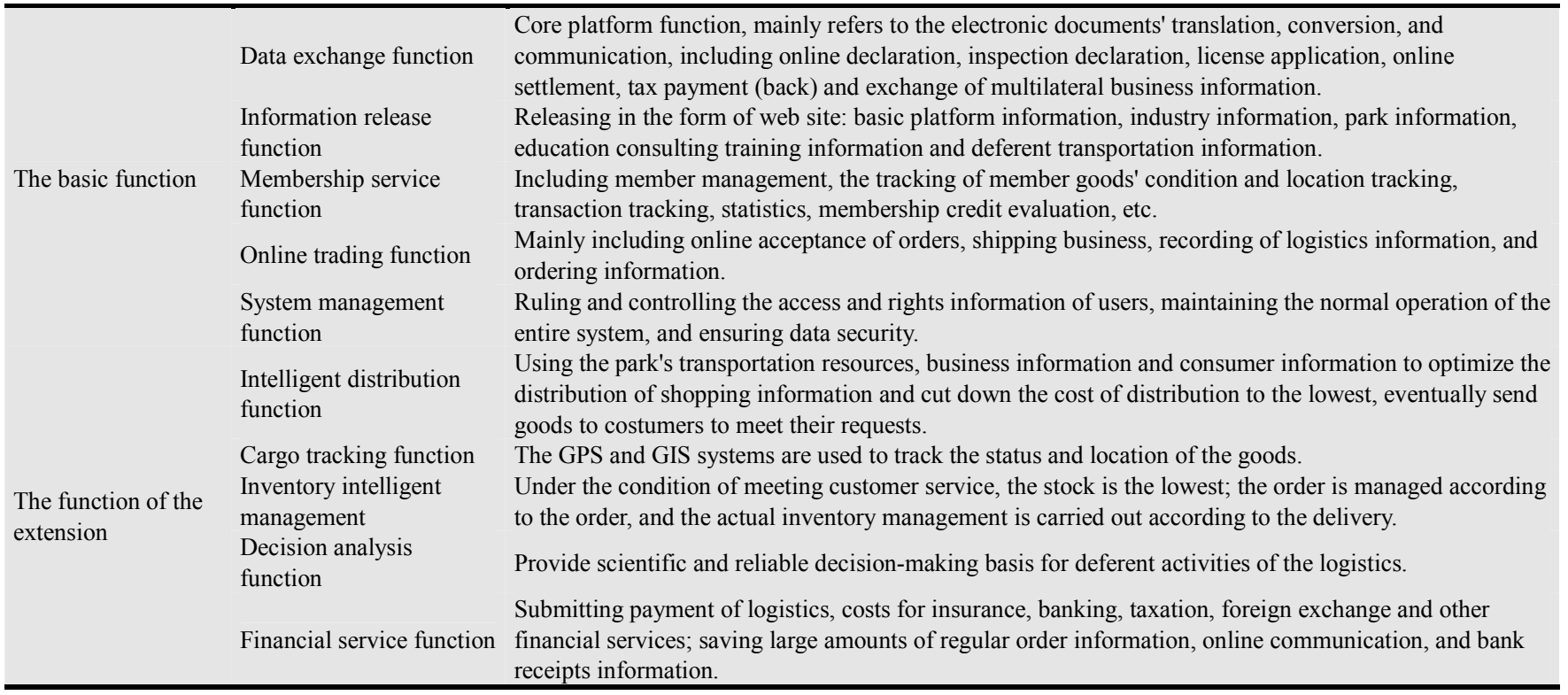

Beijing, Tianjin and Hebei these three places in the Logistics Park has built several deferent kinds of portal site with deferent functions, some of their functions are completely, but others' functions are simple and have drawbacks.

The actual statistics of Beijing-Tianjin-Hebei Logistics Park information platforms is shown in Figure 5. We can find out that the construction of Beijing-Tianjin-Hebei Logistics Park information platform is not perfect from the Figure 5. Apart from the information release function, other functions all have drawbacks in deferent level. Moreover, Beijing-Tianjin-Hebei Logistics Park information platform construction remains in the construction of basic functions, lacking of extended function construction.

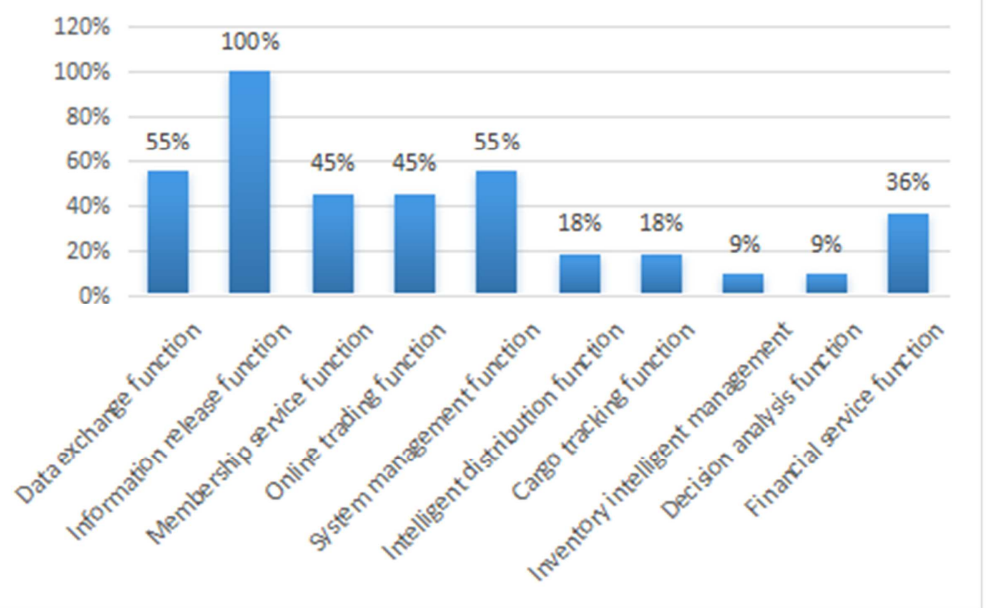

Figure 5. The statistics of Beijing-Tianjin-Hebei Logistics Park information platform function.

\section{The Problems of the Development Within Beijing-Tianjin-Hebei Logistics Park}

\subsection{The Lack of Uniform Standards for Information Construction of Logistics Parks}

As a platform with many logistics enterprises gathered,
Logistics Park produced a large number of operational data, which need to be collected comprehensively. If logistics information data is not standard, normal, unity, it is bound to increase the difficulty of data exchange and reducing logistics information platform for the use efficiency, resulting in distortion of the waste of resources and information in the end. Therefore, it is necessary to speed up the construction of China's logistics information standardization. [9] 


\subsection{The Process of Information Construction of Logistics Park is Slow}

Currently, most of Logistics Parks from Beijing-Tianjin-Hebei do not have own independent portal, and their information mainly linked under other platforms. A large number of the Logistics Parks' understanding level about information-construction is still stand in a poor degree. They think that a computer with some electronic products means that they are standing in the stage. [10]

\subsection{Logistics Park Information Construction Professional Degree is Low}

The Beijing-Tianjin-Hebei most of the logistics enterprises in the park settled in terms of low, small scale logistics enterprises, a table a phone is a logistics company, park management to enterprise's lack of systematic management. Many parks' enterprises are lacking of company personnel and funds. These limitations could inhibit the informatization construction of parks in Beijing-Tianjin-Hebei.

\subsection{The Lack of Compound Talents in the Information Construction of Logistics Park}

The construction of logistics information platform acquires professional talents in logistics information. Therefore, it is necessary to speed up the cultivation of those talents of logistics information. It supposed to enhance the internal personnel of logistics information technology training, so that enterprises can set up effective talent introduction mechanism and incentive mechanism of talent. At the same time, we should cooperate with social education institutions actively, increase the input in the cultivation of the talents about logistics information, train multiple level talents through a variety of ways, and speed up the introduction of logistics information management talents to high quality.

\section{Conclusion}

By analyzing the current situation of Beijing-Tianjin-Hebei Logistics Park Informationization Development, we find out that there are many enterprises need to establish and extend their independent web portal. More methods should be taken into the development of informationization based on the advantages and functions of Logistics Park information platform.

\section{Acknowledgements}

The study is supported by Beijing Key Laboratory of Intelligent Logistics System, (BZ0211), and the project of scientific training program for Beijing Wuzi University college students (2016103051), and Beijing Intelligent Logistics System Collaborative Innovation Center.

\section{References}

[1] Chen Zhijuan. Based on the economic development association mechanism of regional Logistics Park planning method research [D]. Nankai University, 2012.

[2] Logistics Park operation statistical analysis report [J].China Logistics \& Purchasing, 2015, 17: 60-65.

[3] Studied the Logistics Park big data [J]. Transport Business China, 2015, 15:34-35.

[4] Guo Lei. Under the economic globalization of regional logistics research [D]. Hebei normal university, 2008.

[5] Liu Xingjing, Dai He, Yang Dongyuan. Analysis of logistics information platform development planning framework $[\mathrm{J}]$. Logistics technology, 2001(1): 16-18.

[6] Guo Yujie. Research on the construction of Logistics Park based on the development of the Central Plains Economic Zone $[\mathrm{J}]$. Enterprise science and technology and development, 2014(2): 12-13.

[7] Liu Dongying, Cheng Zi. Beijing-Tianjin-Hebei logistics industry upgrade path and countermeasure research $[\mathrm{J}]$. Economy and management, 2015, 04: 18-22.

[8] He Liming. New trend and new countermeasures of Logistics Park Development $[\mathrm{J}]$. China logistics and purchasing, 2015(16): 32-33.

[9] Guo Yujie. Research on the construction of Logistics Park based on the development of the Central Plains Economic Zone $[\mathrm{J}]$. Enterprise science and technology and development, 2014(2): 12-13.

[10] Deng Yaqing, Guo Lan. The coordinated development of Beijing-Tianjin-Hebei in Baoding modern logistics development countermeasures study [J]. Oriental Enterprise Culture: 2015, 07: 236. 